\title{
GENERALIZED AVERAGING OPERATORS AND MATRIX SUMMABILITY
}

\author{
ROBERT E. ATALLA
}

\begin{abstract}
A bounded linear operator $T$ on $C(X), X$ compact, is a g.a.o. if it has associated with it a nonnegative projection $S$ satisfying three conditions given below. An ordinary averaging operator is the case $T=S$. We show that if $T$ is g.a.o., then the following problem has a fairly neat solution: What conditions on an operator $R$ are necessary and sufficient for $\operatorname{kernel}(T) \subset \operatorname{kernel}(R)$ ? Application is made to the problem of the inclusion of one bounded convergence field in another, via the representation of regular matrices as linear operators on $C(\beta N \backslash N)$.
\end{abstract}

1. Introduction. In dealing with problems in matrix summability, it is occasionally useful to consider matrices as inducing linear operators on $C(X)$, the continuous real functions on a certain compact space $X$. (In fact, $X=\beta N \backslash N$. See [A], and $\S 4$ below.) In particular, the problem of the inclusion of the bounded convergence field of one regular matrix in that of another leads to the following problem in operator theory: Given bounded linear operators $T$ and $R$ on $C(X)$ such that $T e=R e=e$ (where $e(x)=1$, all $x \in X$ ), what conditions on $T$ and/or $R$ will imply ker $T \subset \operatorname{ker} R$ (ker= kernel)? In $\S 2$ we show that if $T$ has associated with it a projection $S$ satisfying conditions (I) and (II) of that section, then necessary and sufficient conditions can be given for ' $k e r T \subset \operatorname{ker} R$ '. These conditions have to do with a sort of 'geometric' relation between $R$ and $S$ (Theorem 2.5).

$T$ is called a generalized averaging operator (g.a.o.) if $S$ also satisfies condition (III) of $\S 3$. When $S=T$ we have the usual averaging operator. (See [K]. For more recent references see, e.g., [L].) When (I), (II) and (III) hold, then a certain 'geometric' relation between $S$ and $T$ is given (Theorem 3.2) which will be helpful in identifying operators $T$ to which the preceding theory applies, and in constructing the corresponding projection $S$. In $\S 4$ we apply the theory to regular matrices: Given $T=\left(t_{m n}\right)$ satisfying certain conditions on its rows, we are able to construct the

Received by the editors May 19, 1972 and, in revised form, August 1, 1972.

AMS (MOS) subject classifications (1970). Primary 47B99, 47D15; Secondary 40D25, 40D20.

Key words and phrases. Markov operator, averaging operator, projection, $C(X)$, regular matrix, convergence field, inclusion of convergence fields.

(C) American Mathematical Society 1973 
associated matrix $S$, and give conditions for $C_{T} \subset C_{R}$, where $R=\left(r_{m n}\right)$, and $C_{T}, C_{R}$ are the bounded convergence fields. $\S 5$ has miscellaneous results on g.a.o.

A word on motivation. Most of the results of this paper were first worked out for ordinary averaging operators. Then it was noticed that one could assign the two basic properties of an averaging operator (i.e., (i) $T^{2}=T$, and (ii) $T(f T g)=T f T g$ ) to be a pair of operators in such a way as to satisfy relation $(*)$ in the proof of Lemma 2.2 .

2. Containment of kernels. Throughout the paper, $X$ will be a compact $T^{2}$ space, $C(X)$ the space of real continuous functions on $X$, and $e$ the unit function. $T$ and $S$ will be a pair of bounded linear operators on $C(X)$ with $S \geqq 0$ and $T e=S e=e$, subject to the conditions

(I) $T S=T$, and

(II) $\operatorname{ker} S=\operatorname{ker} T$.

2.1. Notation. Let $t_{x}$ be the regular Borel measure representing the functional $f \rightarrow T f(x)(f \in C(X))$. Thus, $T f(x)=\int f d t_{x}$. Similarly we write $S f(x)=\int f d s_{x}$, etc. Since $T e=S e=e$, we have $1=t_{x}(X)=s_{x}(X)$. We write $\operatorname{car}\left(t_{x}\right)$ for the carrier set of $t_{x}$.

2.2. Lemma. Let $R$ be a bounded linear operator with $R e=e$. The following are equivalent: (a) $\operatorname{ker} T \subset \operatorname{ker} R$; (b) $R S=R$.

Proof. (a) implies (b). Since $T S=T$, or $T(S-I)=0$, we have

$$
S f-f \in \operatorname{ker} T \subset \operatorname{ker} R,
$$

for any $f \in C(X)$. Hence $R(S f-f)=0$ for all $f$, whence $R S=R$.

(b) implies (a). Since $\operatorname{ker} T=\operatorname{ker} S$, this is obvious.

2.3. Corollary. $S^{2}=S$.

Proof. Let $R=S$ in Lemma 2.2.

2.4. RemarK. We have: (I) and (II) imply $S^{2}=S$. Conversely it is easy to check that (II) and $S^{2}=S$ imply (I).

2.5. THEOREM. Let $R$ be a nonnegative linear operator with $R e=e$. The following are equivalent:

(a) $\operatorname{ker} T \subset \operatorname{ker} R$;

(b) for all $x \in X, r_{x} \in \operatorname{co}\left\{s_{y}: y \in \operatorname{car}\left(r_{x}\right)\right\}$, where $\mathrm{co}=$ weak-* closed convex hull.

Proof. (a) implies (b). Let $D$ be the set of all Borel partitions of $X$, directed by refinement. Let $\pi=\left\{A_{1}, \cdots, A_{n}\right\} \in D$. If $A_{i} \cap \operatorname{car}\left(r_{x}\right) \neq \varnothing$, choose $y(i)$ in this set. If $A_{i} \cap \operatorname{car}\left(r_{x}\right)=\varnothing$ (in which case $r_{x}\left(A_{i}\right)=0$ ), let 
$y(i)$ be an arbitrary element of $\operatorname{car}\left(r_{x}\right)$. We define a net of measures $m_{\pi}=$ $\sum r_{x}\left(A_{i}\right) s_{y(i)}$. Since $\sum r_{x}\left(A_{i}\right)=r_{x}(X)=1$, the combination is convex. We show $m_{\pi} \rightarrow r_{x}$ weak-*. Let $f \in C(X)$, and choose $\pi_{0}=\left\{B_{1}, \cdots, B_{m}\right\} \in D$ such that $r, s \in B_{i}$ implies $|S f(r)-S f(s)|<\varepsilon$. Suppose $\pi=\left\{A_{1}, \cdots, A_{n}\right\}$ refines $\pi_{0}$. Since $\operatorname{ker} T \subset \operatorname{ker} R$, Lemma 2.2 implies $R S=R$, and hence

$$
\begin{aligned}
\left|\int f d r_{x}-\int f d m_{\pi}\right| & =\left|R f(x)-\int f d m_{\pi}\right| \\
& =\left|R(S f)(x)-\int f d m_{\pi}\right|=\left|\int S f d r_{x}-\int f d m_{\pi}\right| \\
& =\left|\sum \int_{A_{i}} S f d r_{x}-\sum S f(y(i)) r_{x}\left(A_{i}\right)\right| \\
& \leqq \sum \int_{A_{i}}|S f-S f(y(i))| d r_{x} \leqq \sum \varepsilon r_{x}\left(A_{i}\right)=\varepsilon .
\end{aligned}
$$

Thus, $m_{\pi} \rightarrow r_{x}$ weak-*.

(b) implies (a). Let $f \in \operatorname{ker} T$. By (II), $f \in \operatorname{ker} S$. If $x \in X$, then $\int f d s_{y}=0$ for all $y \in \operatorname{car}\left(r_{x}\right)$, and our condition (b) implies easily that $R f(x)=\int f d r_{x}=$ 0 . Hence $f \in \operatorname{ker} R$, and we have $\operatorname{ker} T \subset \operatorname{ker} R$.

3. Generalized averaging operators. In this section we impose a further condition on the pair $S, T$ :

(III) $S(C(X)) \subset M_{T}$,

where $M_{T}=\{g: T(f g)=T f T g$ for all $f \in C(X)\}$. When (I), (II) and (III) hold, we call $T$ a generalized averaging operator (g.a.o.).

3.1. REMARK. In [A, Theorem 1.2], $M_{T}$ is characterized as the set of $g \in C(X)$ which are constant on each of the sets $\operatorname{car}\left(t_{x}\right)(x \in X)$. Conditions (I) and (III) imply $T(f S g)=T f T(S g)=T f T g$ for all $f, g \in C(X)$. In case $S=T$, we get $T(f T g)=T f T g$, i.e., $T$ is an ordinary averaging operator $[K]$.

3.2. THEOREM. Given bounded operators with $\mathrm{Se}=\mathrm{Te}=e$, the following are equivalent:

(a) (I) and (III) hold;

(b) $y \in \operatorname{car}\left(t_{x}\right)$ implies $s_{y}=t_{x}$ (and hence $S f(y)=T f(x)$ for all $\left.f \in C(X)\right)$.

Proof. (a) implies (b). Let $y \in \operatorname{car}\left(t_{x}\right)$ and $f \in C(X)$. By (III) and the characterization of $M_{T}, S f$ is constant on $\operatorname{car}\left(t_{x}\right)$, so $S f(r)=S f(y)$ for all $r \in \operatorname{car}\left(t_{x}\right)$. Using (I), we have (since $t_{x}(X)=1$ ) $T f(x)=T(S f)(x)=$ $\int S f(r) d t_{x}(r)=S f(y)$. Since $f$ is arbitrary, we have $s_{y}=t_{x}$.

(b) implies (a). To prove (III), let $f \in C(X)$. Clearly, $S f$ is constant on each $\operatorname{car}\left(t_{x}\right)$ (namely, $S f=T f(x)$ on $\operatorname{car}\left(t_{x}\right)$ ). By the characterization of $M_{T}$, this gives $S f \in M_{T}$. To prove (I), $T(S f)(x)=\int S f(y) d t_{x}(y)=$ $\int T f(x) d t_{x}(y)=T f(x)$. Hence $T S=T$.

3.3. REMARKS. (a) As a special case we obtain the following criterion (implicit in $[\mathbf{K}]$ ) for an averaging operator: $T$ is averaging iff $y \in \operatorname{car}\left(t_{x}\right)$ 
implies $t_{y}=t_{x}$. (b) Theorem 3.2 implies that operators satisfying (I) and (III) (and hence all generalized averaging operators) have a rather simple 'geometric' structure which will make the theory especially adaptable to regular matrices. Namely:

3.4. Corollary. Let $T$ and $S$ satisfy (I) and (III). If $x, y \in X$, then either $t_{x}=t_{y}$, or $\operatorname{car}\left(t_{x}\right) \cap \operatorname{car}\left(t_{y}\right)=\varnothing$.

PRoof. If $z \in \operatorname{car}\left(t_{x}\right) \cap \operatorname{car}\left(t_{y}\right)$, then Theorem 3.2 implies $s_{z}=t_{x}$ and $s_{z}=t_{y}$, so $t_{x}=t_{y}$.

\section{Application to matrix summability.}

4.1. Notation. $C^{*}(N)$ is the space of bounded real functions on the positive integers $N$. If $f \in C^{*}(N), f^{\prime}$ is its extension to $\beta N$, the Stone-Cech compactification of $N$, and $f^{*}$ the restriction of $f^{\prime}$ to the compact set $\beta N \backslash N$. If $V \subset N, V^{\prime}$ is its closure in $\beta N$, and $V^{*}=V^{\prime} \cap(\beta N \backslash N) . V^{*} \neq \varnothing$ iff $V$ is infinite, and sets of the form $V^{*}(V \subset N)$ are a basis of open and closed sets for the topology of $N^{*}=\beta N \backslash N$. (See [R] for details.)

$C\left(N^{*}\right)$, the space of continuous real valued functions on $N^{*}$, is isomorphic to the quotient space $C\left(N^{*}\right) / c_{0}$, where $c_{0}$ is the space of real functions on $N$ with limit 0 . If $T=\left(t_{m n}\right)$ is a regular matrix operator on $C^{*}(N)$, then $T\left(c_{0}\right) \subset c_{0}$, and hence $T$ induces an operator $T^{*}$ on $C\left(N^{*}\right)$ by the formula $T^{*} f^{*}=(T f)^{*}\left(f \in C^{*}(N)\right)$. (See, e.g., [A].) From regularity of $T$ it follows easily that $\left(T^{*} e\right)(x)=1$ for all $x \in N^{*}$, where $e(x)=1$ for all $x \in N^{*}$. Let $C_{T}$ be the bounded convergence field of $T$, i.e., the set of $f \in C^{*}(N)$ such that $\lim (m \rightarrow \infty) T f(m)$ exists. Let $\left(C_{T}\right)^{*}=\left\{f^{*}: f \in C_{T}\right\}$. It is easy to see that $\left(C_{T}\right)^{*}=\left\{f \in C\left(N^{*}\right): T^{*} f=\right.$ constant $\}$. If $R$ is another regular matrix, then regularity of $T$ and $R$ implies: $C_{T} \subset C_{R}$ iff $\left(C_{T}\right)^{*} \subset$ $\left(C_{R}\right) *$ iff $\operatorname{ker}\left(T^{*}\right) \subset \operatorname{ker}\left(R^{*}\right)$.

4.2. Remark. The equivalences just mentioned provide the link between matrix summability and the theory of $\S \S 2$ and 3 . We shall show that for a rather large class of nonnegative regular matrices $T=\left(t_{m n}\right), T^{*}$ is a g.a.o. on $C\left(N^{*}\right)$.

The clue is provided by Theorem 3.2 and Corollary 3.4. Suppose $T$ is row finite and satisfies the condition: If $m, p \in N$, then either $t_{m}=t_{p}$, or $\operatorname{car}\left(t_{m}\right) \cap \operatorname{car}\left(t_{p}\right)=\varnothing$ (where $t_{m}$ is the $m$ th row of $T$, considered as a linear functional on $\left.C^{*}(N)\right)$. We define the regular matrix $S=\left(s_{m n}\right)$ as follows: If $m \in \operatorname{car}\left(t_{p}\right)$, then $s_{m}=t_{p}$. If $m \notin \operatorname{car}\left(t_{p}\right)$ for all $p$, then $s_{m}=t_{m}$. We now show that the pair $T^{*}, S^{*}$ satisfy (I), (II), and (III). Since $T$ and $S$ have exactly the same rows (perhaps with different 'multiplicities'), we have $\lim _{m} t_{m}(f)=0$ iff $\lim _{m} s_{m}(f)=0$, and so $\operatorname{ker}\left(T^{*}\right)=\operatorname{ker}\left(S^{*}\right)$. Thus (II) holds. Let $f, g \in C^{*}(N)$ and $n \in N$. Since $m \in \operatorname{car}\left(t_{p}\right)$ implies $s_{m}=t_{p}$, we can show (just as in the proof of '(b) implies (a)' in Theorem 3.2) that $T(S f)(n)=T f(n)$, and $T(f S g)(n)=(T f)(n)(T g)(n)$. Hence $T^{*} S^{*} f^{*}=T^{*} f^{*}$ 
and $T^{*}\left(f^{*} S^{*} g^{*}\right)=\left(T^{*} f^{*}\right) T^{*}\left(S^{*} g^{*}\right)$, so (I) and (III) hold for the pair $T^{*}$, $S^{*}$.

4.3. ReMARK. General considerations of summability theory (see, e.g., [P, p. 82]) permit us to make certain assumptions. Each row of a regular matrix $R=\left(r_{m n}\right)$ may be assumed to have row sum $=1$. Since $\lim _{m} r_{m n}=0$ for each $n$, we may further assume that if $N(m)$ is the least number such that $r_{m N(m)} \neq 0$, then $\lim _{m} N(m)=\infty$. This refers in particular to the matrix $R$ of the following theorem.

4.4. THEOREM. Let the matrices $T$ and $S$ be as in the second paragraph of Remark 4.2. If $R$ is a nonnegative regular matrix, then the following are equivalent:

(a) $C_{T} \subset C_{R}$;

(b) for each $f \in C^{*}(N)$,

$$
\liminf _{m \rightarrow \infty}\left\{\left|r_{m}(f)-s(f)\right|: s \in W_{m}\right\}=0,
$$

where $W_{m}=$ convex hull of $\left\{s_{p}: p \in \operatorname{car}\left(r_{m}\right)\right\}$.

Proof. (b) implies (a). Let $f \in C_{T}=C_{S}$. Adding a suitable constant if needed, we may assume $\lim _{m}(S f)(m)=0$. Given $\varepsilon>0$, choose $M_{1}$ such that $p \geqq M_{1}$ implies $\left|s_{p}(f)\right|<\varepsilon$, and also such that $m \geqq M_{1}$ implies that the inf in (*) is less than $\varepsilon$. Choose $M \geqq M_{1}$ so that $m \geqq M$ implies that $N(m) \geqq M$ $\left(N(m)\right.$ as in 4.3). Now if $m \geqq M$, choose $s \in W_{m}$ so that $\left|r_{m}(f)-s(f)\right|<\varepsilon$. Because $N(m) \geqq M \geqq M_{1}$, we have $|s(f)|<\varepsilon$, and so

$$
\left|r_{m}(f)\right| \leqq\left|r_{m}(f)-s(f)\right|+|s(f)|<2 \varepsilon .
$$

Hence $\lim _{m} R f(m)=0$, i.e., $f \in C_{R}$.

(a) implies (b). If (b) fails, then there exist $f \in C^{*}(N), \varepsilon>0$, and $m(1)<$ $m(2)<\cdots$ such that

$$
\left|r_{m(k)}(f)-s_{p}(f)\right|>\varepsilon
$$

for each $p \in \operatorname{car}\left(r_{(m(k))}\right)$. Taking subsequences if need be, we may assume $\lim _{k} r_{m(k)}(f)=t$ exists. Replacing $f$ by $f-t$, we may assume that $t=0$. (Note that $s_{p}(e)=r_{p}(e)=1$ for all $p$, where $e$ is the unit function on $N$, and that $W_{m}$ is defined by convex combinations.) Let $\{m(a): a \in A\}$ be a subnet of the sequence $\{m(k)\}$ such that $m(a) \rightarrow w$ for some $w \in N^{*}$. By continuity of $R, r_{m(a)}(f) \rightarrow r_{w}\left(f^{*}\right)$, so $r_{w}\left(f^{*}\right)=0$. (Note that $r_{w}\left(f^{*}\right)=R^{*} f^{*}(w)$.) Choose $a_{0} \in A$ such that $a \geqq a_{0}$ implies

$$
\left|r_{m(a)}(f)\right|<\varepsilon / 2 .
$$

Clearly, $\operatorname{car}\left(r_{w}\right) \subset\left[\bigcup\left\{\operatorname{car}\left(r_{m(a)}\right): a \geqq a_{0}\right\}\right]^{*}$, so if $z \in \operatorname{car}\left(t_{w}\right)$, then there is a net $\{p(b): b \in B\}$ such that $p(b) \rightarrow z$ and $p(b) \in \bigcup\left\{\operatorname{car}\left(r_{m(a)}: a \geqq a_{0}\right\}\right.$. By (1) 
and (2), $\left|s_{p(b)}(f)\right| \geqq \varepsilon / 2(b \in B)$. By continuity of $S,\left|s_{z}\left(f^{*}\right)\right| \geqq \varepsilon / 2$. Since $r_{w}\left(f^{*}\right)=0$, we have $s_{z} \neq r_{w}$. It follows from Theorem 2.5 that $\operatorname{ker}\left(T^{*}\right)$ is not contained in $\operatorname{ker}\left(R^{*}\right)$, and hence $C_{T}$ is not contained in $C_{R}$.

4.5. Remark. Regular matrices $A=\left(a_{m n}\right)$ and $B=\left(b_{m n}\right)$ are called equivalent if $\lim _{m} \sum\left|a_{m n}-b_{m n}\right|=0$, in which case $C_{A}=C_{B}$. The result of Theorem 4.4 holds not only for matrices $S$ and $T$ satisfying the conditions stated in 4.3 , but also for any matrices equivalent to these.

4.6. EXAMPLE. We are grateful to the referee for suggesting the following example. Let $T$ be the matrix defined by $T f(m)=(1 / 2)\{f(2 m-1)+f(2 m)\}$. Then the corresponding $S$ will be given by $S f(2 m-1)=S f(2 m)=$ $(1 / 2)\{f(2 m-1)+f(2 m)\}$. Let $R=\left(r_{m n}\right)$ be nonnegative and regular. We shall illustrate the above theory by proving that $C_{T} \subset C_{R}$ iff

$$
\lim \sum_{n}\left|r_{m 2 n-1}-r_{m 2 n}\right|=0 .
$$

Suppose the last condition holds. We shall show that condition (b) of Theorem 4.4 holds, and hence $C_{T} \subset C_{R}$. Define a new matrix $W$ by the formula $w_{m 2 n-1}=w_{m 2 n}=r_{m 2 n-1}$. Now $\lim _{m} \sum_{n}\left|w_{m n}-r_{m n}\right|=0$, so that for all $f \in C^{*}(N)$ we have

$$
\lim _{m}\{W f(m)-R f(m)\}=0 .
$$

Moreover, $W$ is nonnegative and regular, and there is no loss of generality in assuming that $\sum_{n} w_{m n}=1$ for all $m$, and that $R$ and $W$ are both rowfinite. But each row of $W$ is a convex combination of rows of $S$ :

$$
\left(w_{1}, w_{2}, \cdots\right)=2 w_{1}\left(\frac{1}{2}, \frac{1}{2}, \cdots\right)+2 w_{3}\left(0,0, \frac{1}{2}, \frac{1}{2}, 0, \cdots\right)+\cdots .
$$

Hence formula $(* *)$ implies formula $(*)$ of Theorem 4.4 . The converse can be proved directly, without use of 4.4 . We give the basic idea without going into detail. Assume $C_{T} \subset C_{R}$, let $m$ be fixed, and let $f(n)=$ sgn $\left|r_{m 2 n}-r_{m 2 n-1}\right|$. Then

$$
\sum_{n}\left|r_{m 2 n}-r_{m 2 n-1}\right|=\sum_{n}\left(r_{m 2 n}-r_{m 2 n-1}\right) f(n)=\sum_{n} r_{m n} g(n),
$$

with $g \in C_{T}$, and $T-\lim g=0$. (There is a minor difficulty in that $g$ depends on $m$.)

5. Miscellaneous results. Theorem 5.1 shows to what degree the projection $S$ is determined by conditions (I) and (III). Theorem 5.3 shows that if $T$ is a g.a.o. satisfying a rather mild invariance condition, then it cannot converge in the mean to a projection unless it is itself a projection.

5.1. THEOREM. Suppose both pairs $T, S$ and $T, W$ satisfy (I) and (III). Then for all $f \in C(X), S f|K=W f| K$, where $K=\mathrm{cl} \bigcup\left\{\operatorname{car}\left(t_{x}\right): x \in X\right\}$. 
PRoof. By Theorem 3.2, if $y \in \operatorname{car}\left(t_{x}\right)$, then $s_{y}=t_{x}$ and $w_{y}=t_{x}$, so $s_{y}=$ $w_{y}$, whence $S f(y)=W f(y)(f \in C(X))$.

5.2. THEOREM. Let $T$ be a g.a.o. Suppose that $\operatorname{ker}(T) \subset \operatorname{ker}(R)$, and also that for all $x \in X$ we have $\operatorname{car}\left(r_{x}\right) \subset \operatorname{car}\left(t_{x}\right)$. Then $R=T$.

Proof. By Theorem 3.2, $y \in \operatorname{car}\left(t_{x}\right)$ implies $s_{y}=t_{x}$. By Theorem 2.5, $r_{x} \in \operatorname{co}\left\{s_{y}: y \in \operatorname{car}\left(r_{x}\right)\right\} \subset \operatorname{co}\left\{s_{y}: y \in \operatorname{car}\left(t_{x}\right)\right\}=\left\{t_{x}\right\}$. Hence $r_{x}=t_{x}(x \in X)$, so $R=T$.

\subsection{TheOREM. Let $T$ be a g.a.o. Suppose}

(i) $P=\lim _{n} 1 / n\left(T+\cdots+T^{n}\right)$ exists in the strong operator topology;

(ii) $y \in \operatorname{car}\left(t_{x}\right)$ implies $\operatorname{car}\left(t_{y}\right) \subset \operatorname{car}\left(t_{x}\right)$.

Then $T=P\left(\right.$ and hence $\left.T^{2}=T\right)$.

Proof. First we show that $\operatorname{car}\left(t_{n x}\right) \subset \operatorname{car}\left(t_{x}\right)(x \in X)$ (where $t_{n x}$ is the measure representing the functional $f \rightarrow T^{n} f(x)$ ). Now

$$
\begin{aligned}
T(T f)(x) & =\int_{\operatorname{car}\left(t_{x}\right)} T f(y) d t_{x}(y) \\
& =\int_{\operatorname{car}\left(t_{x}\right)} \int_{\operatorname{car}\left(t_{y}\right)} f(r) d t_{y}(r) d t_{x}(y) \\
& =\int_{\operatorname{car}\left(t_{2 x}\right)} f d t_{2 x},
\end{aligned}
$$

whence, easily, $\operatorname{car}\left(t_{2 x}\right) \subset \mathrm{cl} \bigcup\left\{\operatorname{car}\left(t_{y}\right): y \in \operatorname{car}\left(t_{x}\right)\right\} \subset \operatorname{car}\left(t_{x}\right)$, the last inclusion by hypothesis. By induction we get $\operatorname{car}\left(t_{n x}\right) \subset \operatorname{car}\left(t_{x}\right)(x \in X)$. (In the induction step, we compare the integral expressions of both sides of the equation $T^{n+1} f(x)=T\left(T^{n} f\right)(x)$, as we just did for the case $n=1$.) Since $(1 / n) \sum_{k=1}^{n} t_{k x} \rightarrow p_{x}$ weak-*, we have $\operatorname{car}\left(p_{x}\right) \subset \mathrm{cl} \bigcup\left\{\operatorname{car}\left(t_{n x}\right): n \in N\right\} \subset \operatorname{car}\left(t_{x}\right)$. Clearly, $\operatorname{ker}(T) \subset \operatorname{ker}(P)$. Theorem 5.2 implies $T=P$.

\section{REFERENCES}

[A] R. E. Atalla, On the multiplicative behavior of regular matrices, Proc. Amer. Math Soc. 26 (1970), 437-446. MR 42 \#6633.

[K] J. L. Kelley, Averaging operators on $C_{\infty}(X)$, Illinois J. Math. 2 (1958), 214-223. MR 21 \#2179.

[L] S. P. Lloyd, On extreme averaging operators, Proc. Amer. Math. Soc. 14 (1963), 305-310. MR 28 \#2451.

[P] G. M. Petersen, Regular matrix transformations, McGraw-Hill, New York and London, 1966. MR 37 \#642.

[R] W. Rudin, Homogeneity problems in the theory of Čech compactifications, Duke Math J. 23 (1956), 409-419. MR 18, 324.

Department of Mathematics, Ohio University, Athens, Ohio 45701 